\title{
Influence of Temperature on Contact Pressures and Resource of Metal-Polymer Plain Bearings with the Filled Polyamide PA6 Bushing
}

\author{
Myron Chernets ${ }^{1, *}$, Mykhaylo Pashechko ${ }^{2}$, Anatolii Kornienko ${ }^{1}$ and Andrei Buketov ${ }^{3}$ \\ 1 Department of Applied Mechanics and Materials Engineering, National Aviation University, 03058 Kyiv, \\ Ukraine; myron.czerniec@gmail.com (M.C.); anatoliykor80@gmail.com (A.K.) \\ 2 Department of Fundamentals of Technology, Lublin University of Technology, 20-816 Lublin, Poland; \\ mpashechko@hotmail.com \\ 3 Department of Transport Technologies, Kherson State Maritime Academy, 73000 Kherson, Ukraine; bu- \\ ketov@tntu.edu.ua \\ * Correspondence: myron.czerniec@gmail.com
}

\begin{abstract}
It is known that the elastic characteristics of polyamides change with increasing temperature, in particular, the Young's modulus decreases significantly. This fact is practically not taken into account in design calculations of metal-polymer plain (MP) bearings, operating under conditions of the boundary and dry friction. The purpose of the study is the analysis of the effect of temperature on the change of the Young's modulus and, accordingly, the contact strength and triboresource according to the developed method of calculating MP bearings. MP bearings with a bushing made of polyamide PA6 reinforced with glass or carbon dispersed fibers were investigated. Quantitative and qualitative regularities of change of the maximum contact pressures and resource of the bearings at temperature increase under conditions of boundary and dry friction are established. The pressures in the bearing bushing made of PA6+30GF will be lower than for the bushing made of PA6+30CF. The resource of the bushing made of PA6+30CF will be significantly greater than for PA6+30GF. For thermoplastic polymers, the increase in temperature will have a useful practical effect due to the decrease in the rigidity of the polymer composites of the bearing bushing.
\end{abstract}

Keywords: metal-polymer plain bearings; PA6 based polyamide composites; dispersed glass and carbon fibers; temperature; Young's modulus; maximum contact pressures and resource; boundary and dry friction

\section{Introduction}

Metal-polymer (MP) plain bearings, which have been known since the 1930s, are quite common in modern conditions due to their characteristic positive qualities. These include: sufficiently large load capacity, the possibility of use in dry friction and in a variety of special technological and operational conditions, under shock loads, small axial dimensions in comparison with their diameter, low noise level, damping ability, etc. They are able to operate in a wide range of temperatures, both low and high.

Various types of thermoplastic polymers and composites based on them are used as the material of MP bearing bushings, in particular polyamides PA6, PA46, PA66. To increase the strength and wear resistance of polymers, fillers of various types and structures (glass and carbon fiber, bronze powder, molybdenum disulfide, graphite, PTFE, polyethylene, and even semiconductor materials) are used [1-7]. As a result of modification by one or more fillers, significantly higher wear resistance, reduction of the sliding friction coefficient, increase of strength characteristics in comparison with basic polymers are achieved. It should be noted that these performance characteristics of both unmodified and modified polymers are influenced by temperature. In addition, the temperature 
affects the elastic characteristics of polymeric materials. It is known that as the temperature decreases, the polymer materials become harder due to an increase in the Young's modulus and a decrease in the Poisson's ratio. As it increases, the Young's modulus will decrease and the Poisson's ratio will increase, i.e. the polymers become more deformable. However, despite the rather large area of distribution and scope of MP bearing, the question of the impact of changes in these elastic characteristics of polymer composites, in particular polyamide, under the influence of temperature on their life and the bearing capacity remains poorly understood. It is known [1] that the temperature significantly affects the decrease in the Young's modulus of polyamides.

A priori, it can be argued that with decreasing Young's modulus and increasing Poisson's ratio due to increasing temperature, the contact pressures in the MP bearing will be lower, because these mechanical characteristics of the polymer bushing are in the expressions for their calculation in contact mechanics. It is logical to assume that the MP bearing life will increase at a temperature higher than normal. However, this type of research for MP bearings is absent in the literature as well as the corresponding effective analytical methods for their implementation. It should be noted that the computational $[8-15$, etc.] or numerical methods for the study of metal plain bearings $[1,16,17]$ have not been used in the calculation of metal-polymer plain bearings. In numerical methods of research of metal-polymer plain bearings [18-20] the estimation of contact pressures is carried out, however there is no possibility of their resource determination.

It should be noted that in the experimental study of MP bearings, in addition to the analysis of polymer bushing wear and sliding friction coefficient, some authors also assess the temperature in the bearing and its effect on these tribotechnical characteristics of various polymer composites [2-5, etc.] in particular PA6 based composites [2,3].

Since the problem of estimating the influence of the temperature factor on the bearing capacity and resource of MP bearings is of great practical importance, the developed analytical method [21-25] for studying the contact strength and frictional stability of this type of sliding tribosystems was used. It is based on the methodology of research of wear kinetics at sliding friction and author's methods of calculation of sliding bearings with metal elements [22,25-27]. The article investigates MP bearings with bushings made of composites PA6+30\%GF, PA6 $+30 \% \mathrm{CF}$, modified with glass and carbon fibers correspondingly.

\section{Materials and Methods}

\subsection{Influence of temperature}

The influence of temperature on the contact pressures and the resource of MP bearings is based on changes in the elastic characteristics of polymer materials. Such changes for the modulus of elasticity $E$ and Poisson's ratio $\mu$ of polyamide PA6 and PA6 based composites PA6+30\%GF, PA6+30\%CF at $T=25-55{ }^{\circ} \mathrm{C}$ and relative humidity of $50 \%$ are given in Table 1.

Table 1. Influence of temperature on the modulus of elasticity and Poisson's ratio

\begin{tabular}{cccccccc}
\hline $\begin{array}{c}\text { Materials } / \\
\text { temperature, } \mathbf{T}^{\circ} \mathbf{C}\end{array}$ & $\mathbf{2 5}$ & $\mathbf{3 5}$ & $\mathbf{4 5}$ & $\mathbf{5 5}$ & $\begin{array}{c}\text { Decrease } \\
\boldsymbol{E} \text {, times }\end{array}$ & $\begin{array}{c}\text { Poisson's } \\
\text { ratio }^{1}, \boldsymbol{\mu}\end{array}$ & $\begin{array}{c}\text { Increase } \boldsymbol{\mu} \\
\text { times }\end{array}$ \\
\hline PA6 & 2700 & 2550 & 2400 & 2050 & 1,32 & $0,39 / 0,416$ & 1,067 \\
$\mathrm{PA} 6+30 \% \mathrm{GF}$ & 3900 & 3750 & 3500 & 3000 & 1,3 & $0,42 / 0,438$ & 1,043 \\
$\mathrm{PA} 6+30 \% \mathrm{CF}$ & 5400 & 5270 & 5150 & 4450 & 1,21 & $0,4 / 0,418$ & 1,045 \\
\hline
\end{tabular}

${ }^{1}$ Poisson's ratio $\mu$ at 25 and $55{ }^{\circ} \mathrm{C}$

The operating temperature in the metal-polymer plain bearings should not exceed $60^{\circ} \mathrm{C}$, as this can lead to their thermal aging. The decrease in the modulus of elasticity, i.e. the decrease in rigidity, is more than $30 \%$ for PA6 and PA6+30\%GF, while for 
PA6 $+30 \%$ CF this decrease is smaller. As for the increase in the Poisson's ratio, i.e. the increase in plasticity, it is insignificant.

\subsection{Calculation of contact pressures}

To conduct a study on the calculation of maximum contact pressures, the author's method of contact mechanics [21-25] on the internal contact of close radii cylindrical bodies was used. This contact occurs in the plain bearing. The view and diagram of the $\mathrm{MP}$ bearing is shown in Figure 1.

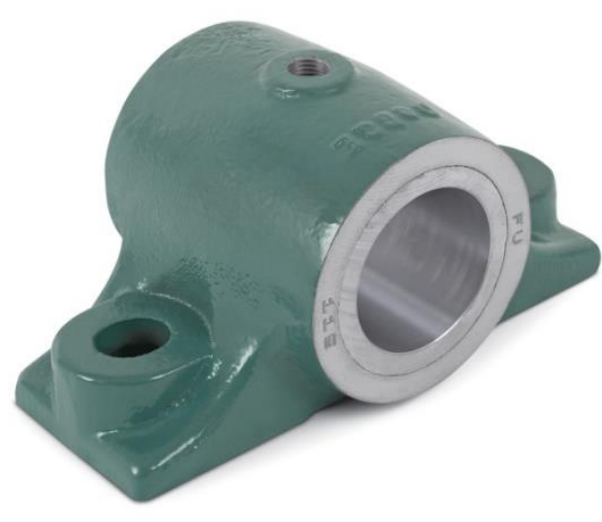

(a)

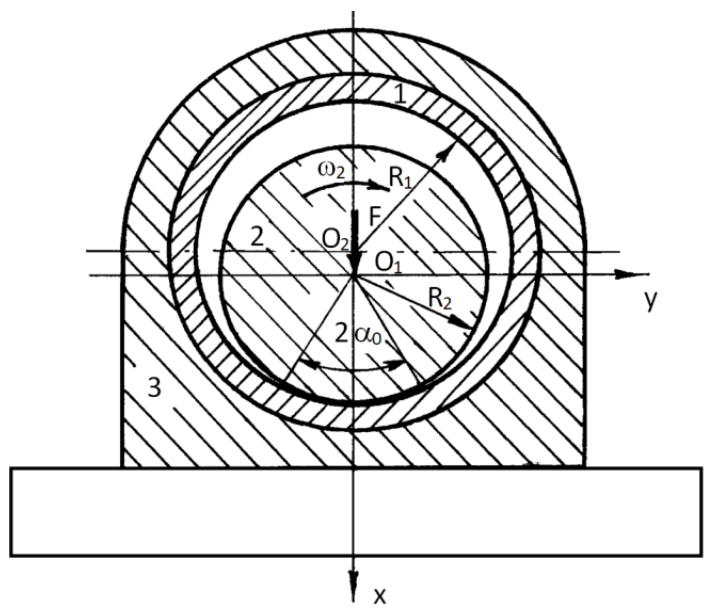

(b)

Figure 1. Metal-polymer plain bearing: (a) General view; (b) Diagram (1-composite bushing, 2 - shaft, 3 - housing)

A static load $N$ acts on the shaft 2 of the MP bearing. Since the plane contact problem of the elasticity theory is considered, the total load $N$ is reduced to a single $F=N / l$, where $l$ is the length of the shaft journal. The bearing has a guaranteed initial radial clearance $\varepsilon=$ $R_{1}-R_{2} \geq R$. Accordingly, $R_{1}$ is the inner radius of the bushing 1 , and $R_{2}$ is the radius of the shaft 2 . In MP bearings, the shafts are metal and the bushings are non-metallic. It should be noted that the strength characteristics of the shaft and the bushing materials differ significantly (8 - 10 times) and the modulus of elasticity (40 - 100 times), which has a fundamental effect on the contact parameters. It is also known that in metal-polymer tribocouples polymer composites have 3-4 orders of magnitude lower wear resistance than steel. External load leads to the contact interaction of the shaft elements, resulting in appearance of the contact pressure $p(\alpha)$ unknown by magnitude and distribution acting on the contact arc $2 R_{2} \alpha_{0}$. That is, the task is to determine the specified contact parameters.

In the general equation for determining the contact pressure in the contact area [22, 25] was used the following function:

$$
p(\alpha) \approx E_{0} \varepsilon \sqrt{\tan ^{2} \frac{\alpha_{0}}{2}-\tan ^{2} \frac{\alpha}{2}}
$$

where $E_{0}=\left(e / R_{2}\right) \cos ^{2}\left(\alpha_{0} / 4\right), e=4 E_{1} E_{2} / Z, Z=\left(1+\kappa_{1}\right)\left(1+v_{1}\right) E_{2}+\left(1+\kappa_{2}\right)\left(1+v_{2}\right) E_{1}, \alpha$ is the polar angle, $E_{1}, E_{2}$ - modulus of elasticity; $v_{1}, v_{2}$ - Poisson's ratios; $\kappa=3-4 v$.

The bearing capacity of the bearing is characterized by the level of maximum contact pressures $p(0)$, and they occur at $\alpha=0$. That is

$$
p(0) \approx E_{0} \varepsilon \tan \left(\alpha_{0} / 2\right)
$$

The contact semiangle $\alpha_{0}$ is determined from the equilibrium condition of external load $F$ and contact pressures $p(\alpha)$. Taking into account expression (2), it is: 


$$
F=R_{2} \int_{-\alpha_{0}}^{\alpha_{0}} p(\alpha) \cos \alpha d \alpha=4 \pi R_{2} E_{0} \varepsilon \sin ^{2}\left(\alpha_{0} / 4\right)
$$

When the shaft rotates at a constant angular velocity $\omega_{2}$ the parameters of the static contact, i.e. the contact pressures $p(\alpha)$ and the contact angle $2 R_{2} \alpha_{0}$, will change due to wear of the composite bushing. Accordingly, there will be a decrease in $p(\alpha)$ and an increase in the contact area $2 R_{2} \alpha_{0}$. According to [22 - 26] wear contact pressures is

$$
p(\alpha, t, h)=p(\alpha)+p(h),
$$

where $p(h)$ is the change in initial pressures due to wear.

The law of change $p(h)$ is chosen as follows

$$
p(h)=E_{h} \varepsilon_{h} \sqrt{\tan ^{2} \frac{\alpha_{0 h}}{2}-\tan ^{2} \frac{\alpha}{2}},
$$

where $E_{h}=c_{h}\left(e_{4} / R_{2}\right) \cos ^{2}\left(\alpha_{0 h} / 4\right), c_{h}>0$ is the wear rate indicator.

The tribocontact semiangle $\alpha_{0 h}$ characterizing the wear zone during wear is determined by condition (6)

$$
F=4 \pi R_{2} E_{0}\left(\varepsilon+c_{\alpha h} \varepsilon_{h}\right) \sin ^{2}\left(\alpha_{0 h} / 4\right),
$$

where $\varepsilon_{h}=h_{k \max }\left(-K_{t}^{(\mathrm{k})}+h_{k}^{\prime}\right) ; h_{1}^{\prime}=h_{2} / h_{1}, h_{2}^{\prime}=h_{1} / h_{2}$ - relative wear in the tribosystem; $K_{t}^{(1)}=1, K_{t}^{(2)}=\alpha_{0} / \pi$ - coefficients of mutual overlap of bearing elements; $c_{\alpha h}$ - indicator of the tribocontact angle growth rate; $h_{k \max }$ - acceptable wear of elements 1 and 2 of the bearing;

$$
h_{1}^{\prime}=\frac{B_{1} \tau_{10}^{m_{1}}\left(\tau-\tau_{20}\right)^{m_{2}}}{B_{2} \tau_{20}^{m_{2}}\left(\tau-\tau_{10}\right)^{m_{1}}} K_{t}^{(2)}, h_{2}^{\prime}=\frac{B_{2} \tau_{20}^{m_{2}}\left(\tau-\tau_{10}\right)^{m_{1}}}{B_{1} \tau_{10}^{m_{1}}\left(\tau-\tau_{20}\right)^{m_{2}}} K_{t}^{(1)},
$$

where $\tau=f p(0)$ - Coulomb specific friction force, $f$ - sliding friction coefficient, $B_{k}, m_{k}, \tau_{k 0}$ - wear resistance characteristics of the tribocouple materials under the accepted external conditions of triboexperimental research; $k$-numbering of the bearing elements (Figure 1b).

\subsection{Calculation of resource}

The calculation of the MP bearing resource when the bushing wears to $h_{1}=h_{k \max }$ is carried out according to the formula

$$
t=\frac{-B_{k} \tau_{k o}^{m_{k}}}{v c_{h} \tau(h) \Sigma_{k}\left(1-m_{k}\right) K_{t}^{(k)}}\left\{\left[\tau-\tau_{k 0}\right]^{1-m_{k}}-\left[\left(\tau-\tau_{k 0}\right)+c_{h} h_{k \max } \Sigma_{k} \tau_{h}(h)\right]^{1-m_{k}}\right\},
$$

where $v=\omega_{2} R$ is the sliding speed; $C h$ is the coefficient of wear rate; $\Sigma_{1}=\left(-K_{t}^{(1)}+h_{1}^{\prime}\right), \Sigma_{2}=\left(K_{t}^{(2)}-h_{2}^{\prime}\right) ; \tau(h)=f p(0, t, h)=f E_{h} \tan \left(\alpha_{0 h} / 2\right)$ is the maximum specific friction force in tribocontact.

\subsection{Conditional calculation of bearing capacity}

In modern mechanical engineering in the design of metal plain bearings two main criteria: the average pressure $p$ (as its bearing capacity) and Zeiner's $p v$ are used. The average contact pressure $p$ is considered to be evenly distributed over the contact area $2 R_{2} l$

$$
p=\frac{N}{2 R_{2} l}=\frac{F}{D_{2}} \leq[p]
$$


where $[p]$ is the allowable value of the contact pressure of less durable material (reference parameter).

From formula (9) it follows that the contact arc of length $2 R_{2}=D_{2}$ corresponds to the contact angle $2 \alpha_{0}=360^{\circ} / \pi \approx 114.6^{\circ}=$ const, which does not depend on the properties of the bearing materials. It should be noted that such a significant contact angle is achieved at significant bearing loads and minimal radial clearances. Accordingly, this is confirmed in the works available in the literature [1, 8 - 20, etc.] and the author's works [22-27], based on the methods of contact elasticity theory. It is also known that in plain bearings the magnitude and distribution of contact pressures are significantly influenced by the radial clearance and the elastic characteristics of the shaft and bushing materials. Actually, these significant factors of influence are absent in formula (9).

Also known is a modified formula [28] for determining the maximum pressure $p_{\max }$ in the bearing

$$
p_{\max }=\frac{4}{\pi} \frac{N}{D_{2} l}=\frac{4}{\pi} \frac{F}{D_{2}}
$$

Here it is assumed that the pressure varies according to the law of cosine, and the contact arc $2 \alpha_{0}=180^{\circ}$. The structure of formula (10) is the same as formula (9). The maximum pressure $p_{\max }$ according to (10) will be 1,273 times higher than the average pressure $p$. It was also established [11] that at zero clearance in the cylindrical conjugation at static contact $2 \alpha_{0} \approx 170^{\circ}$. However, there must be a certain radial clearance in the plain bearing, because without it its reliable operation is impossible.

That is, the simplified conditional methods for calculating plain bearings according to the criterion of contact pressure $p$ do not allow objective assessing the actual pressure level. Their use in the case of MP bearings seems unreasonable. For this purpose, it is reasonable to use the above presented in paragraph 2.2, the classical analytical method of the contact mechanics of close radii cylindrical bodies with internal contact.

\section{Solution, results, discussion}

Data for the calculation of MP bearings: $N=500,1000,1500 \mathrm{~N} ; F=N / l ; D_{2}=30 \mathrm{~mm}$; $l=D_{2} ; \varepsilon=0.2 \mathrm{~mm} ; n_{2}=60 \mathrm{rpm}$ is the shaft rotational speed; $f_{G F}=f_{C F}=0.3$ under dry friction; $h_{1 \max }=1.0 \mathrm{~mm}$ is the acceptable bushing wear.

Materials of metal-polymeric bearings: shaft - steel $45(0.45 \% \mathrm{C})$ normalized, grinding; $E_{2}=210 \mathrm{GPa}, \mu_{2}=0.3 ; B_{2}=10^{13}, m_{2}=2, \tau_{20}=0.1 \mathrm{MPa}$. Bushing: 1) carbon-filled polyamide PA6+30\%CF, $E_{C F}=5.20 \mathrm{GPa}, \mu_{C F}=0.42, B_{1 C F}=24 \cdot 10^{10}, m_{1 C F}=1.9, \tau_{10}=0.05$ MPa; 2) glass-filled polyamide PA6+30\%GF, $E_{G F}=3.90 \mathrm{GPa}, \mu_{G F}=0.42, B_{1 G F}=6.67 \cdot 10^{10}$, $m_{1 G F}=1.9, \tau_{10}=0.05 \mathrm{MPa}[29,30]$; volume filler content $-30 \%$.

The example of the calculation examines friction both with greasing (boundary) and without greasing (dry). The mode of dry friction is widespread and dominant in MP bearings due to self-lubrication of polymeric materials. It is possible, if necessary, to use in this type of bearings greasing with the implementation of boundary friction. In this case, for these hybrid combinations steel - polymer composite in the calculated ratios of the presented method, you only need to use the sliding friction coefficients corresponding to this type of lubrication. Instead, the established wear resistance characteristics $B, m, \tau_{0}$ of these polymer composites remain the same, because they were set for the range of change $=0.2 \ldots 4 \mathrm{MPa}$.

Figures $2-10$ present the results of calculations. Accordingly, Figure 2 shows the effect of temperature on the change of maximum contact pressures at different levels of external load. 


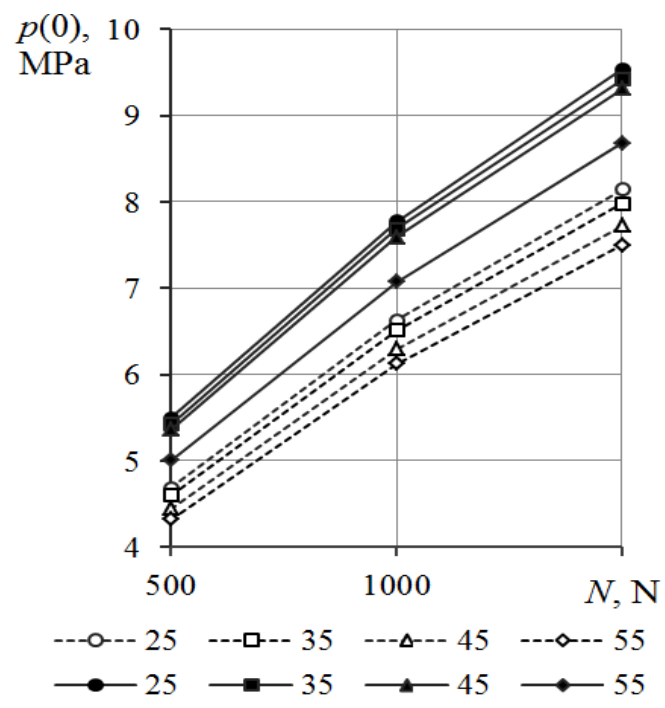

Figure 2. Influence of ambient temperature on maximum contact pressures: $\mathrm{PA} 6+30 \% \mathrm{CF}-$ in solid lines, PA6+30\%GF - in dashed lines

Quantitative growth of $p(0)$ is almost the same at different temperature levels. It is established that in the case of MP bearing with a bushing made of carbon composite PA6 $+30 \% \mathrm{CF}$ the pressure at temperature $T=25^{\circ} \mathrm{C}$ will be 1.1 times lower than at $T=55^{\circ} \mathrm{C}$. For fiberglass bushings, this difference is almost the same, as it is 1,085 times. In the case of a bushing made of carbon composite, the maximum contact pressures in the bearing will be $1.17 \ldots 1.18$ times higher than for a glass composite bushing at all investigated operating loads. The maximum contact pressures $p(0)$ in the MP bearings depend nonlinearly on the load $N$. An increase in load $N$ by 3 times causes an increase in $p(0)$ by 1,736 times, ie $\approx \sqrt{3}$.

When the bushing wears during the operation, the initial pressures $p(0)$ will decrease. Accordingly, Figure 3 shows the tribocontact pressures when reaching the accepted allowable bushing wear $h_{1 \max }$.

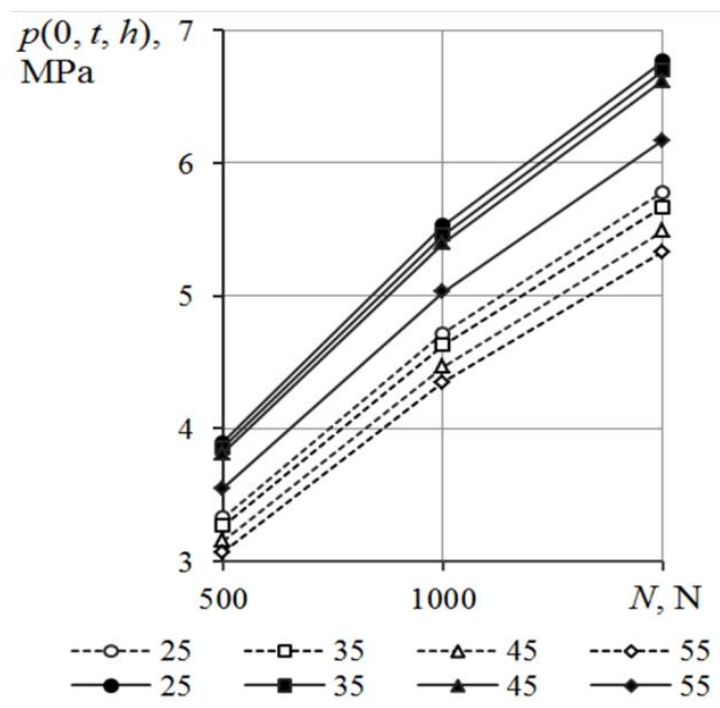

Figure 3. Influence of ambient temperature on maximum wear contact pressures

Regarding the patterns of maximum wear contact pressures $p(0, t, h)$ change due to polymer bushing wear or with increasing load, they will be similar both qualitatively and quantitatively as in the case of the initial maximum contact pressures $p(0)$ (Figure 2).

The initial semiangles $\alpha_{0}$ were also calculated (Figure 4). It was established that in a bearing with a glass-composite bushing they will be, accordingly, up to 1.18 times 
smaller than in the presence of a carbon-composite bushing. With increasing load $\alpha_{0}$ increases as $p(0)$, i.e. by 1,736 times.

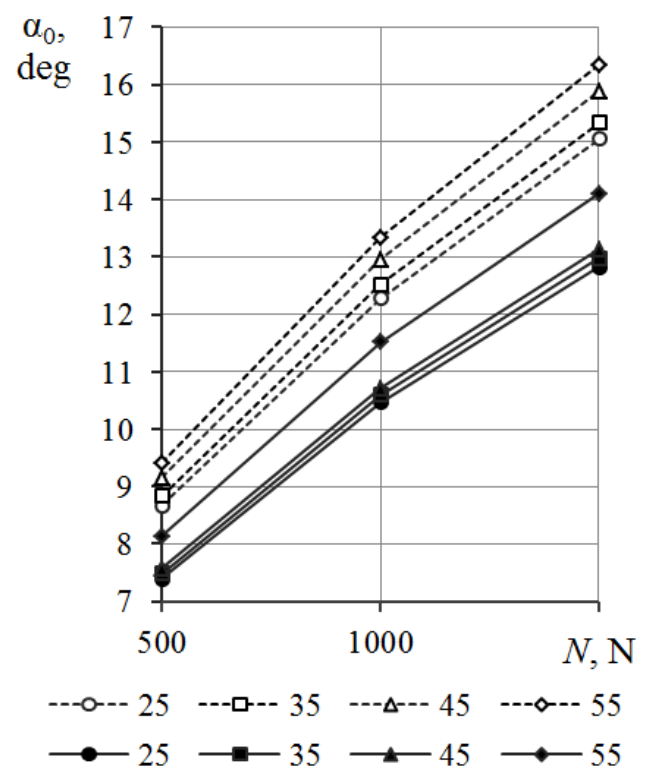

Figure 4. Influence of ambient temperature on the contact semiangle

Wear of the composite bushing leads to an increase in the initial contact semiangles $\alpha_{0}$ (Figure 5). Qualitative and quantitative patterns of their increase are preserved, inverted to those that occur when the wear contact pressures $p(0, t, h)$ decrease.

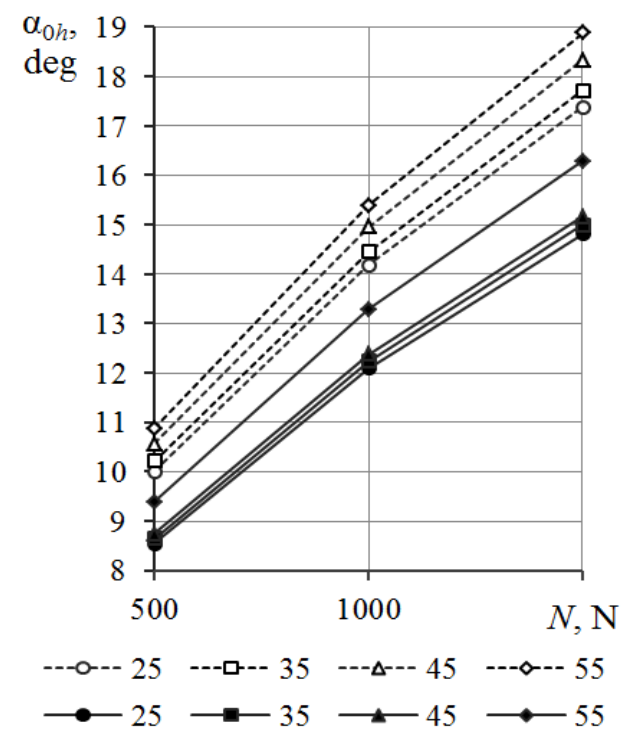

Figure 5. Influence of ambient temperature on change of contact semiangle due to bushing wear

As a result of solving the problem by Eq. (8), a predictive estimation of the resource of the MP bearing with bushings PA $6+30 \% \mathrm{CF}$ and PA $6+30 \% \mathrm{GF}$ for both types of friction was performed.

Figs. 6 and 7 show the dependence of the bearing resource on the temperature at the acceptable wear $h_{1 \max }=1.0 \mathrm{~mm}$ for the boundary friction at different load levels. 


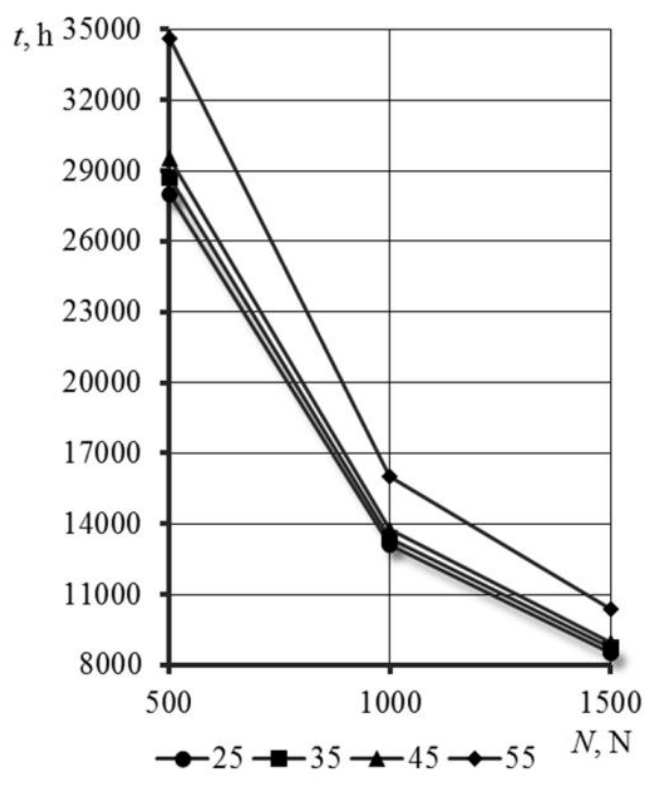

(a)

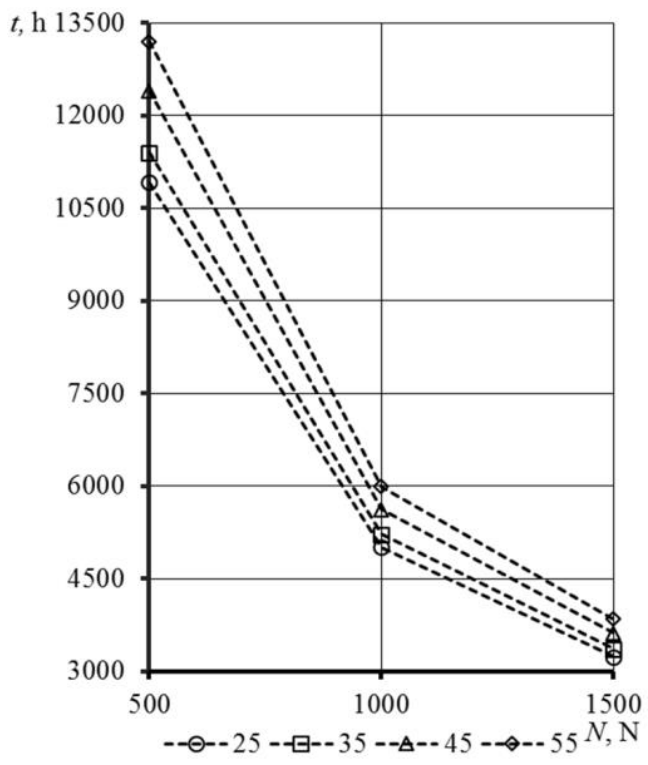

(b)

Figure 6. Influence of ambient temperature on the bearing resource (boundary friction): (a) PA6+30\%CF; (b) PA6+30\%GF

Quantitative growth of the resource with increasing ambient temperature will be $22 \%$ in the bearing with a carbon composite bushing and $20 \%$ with a glass composite bushing. At all loads such dependences are practically identical.

Figure 7 shows the resource of both MP bearings. The resource of a bearing with a carbon composite bushing is much longer.

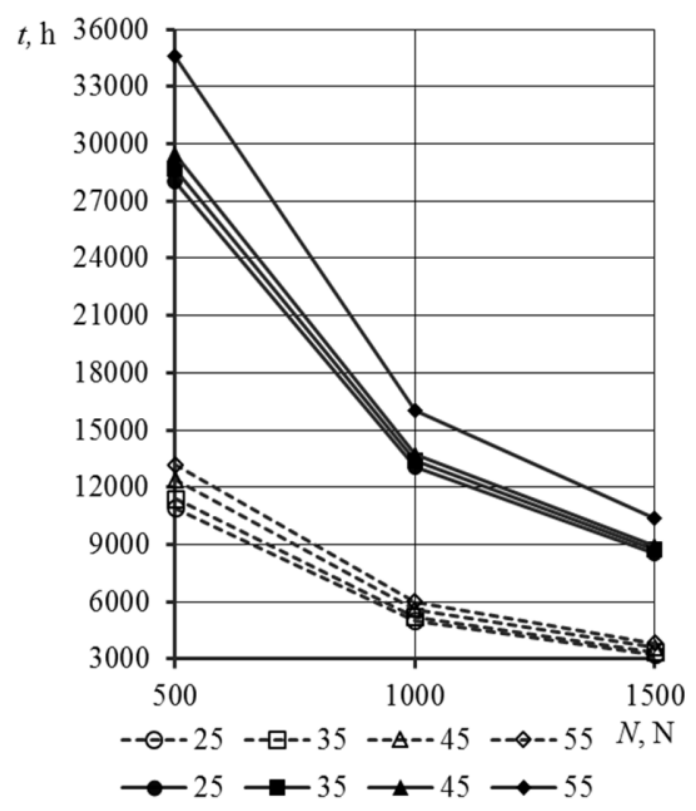

Figure 7. Comparison of the bearing resources under boundary friction

The ratio of resources of both MP bearings under boundary friction will be approximately the same for all loads at $T=25-45^{\circ} \mathrm{C}$ : at $N=500 \mathrm{~N}$ it is $240 \ldots 256 \%$, at $N=$ $1000 \mathrm{~N}$ it is $245 \ldots 261 \%$, at $N=1500 \mathrm{~N}$ it is $247 \ldots 264 \%$. At $T=55^{\circ} \mathrm{C}$ for all loads $N$ this ratio is higher up to $270 \%$.

Accordingly, Figures 8 and 9 show the bearing resource under dry friction. 


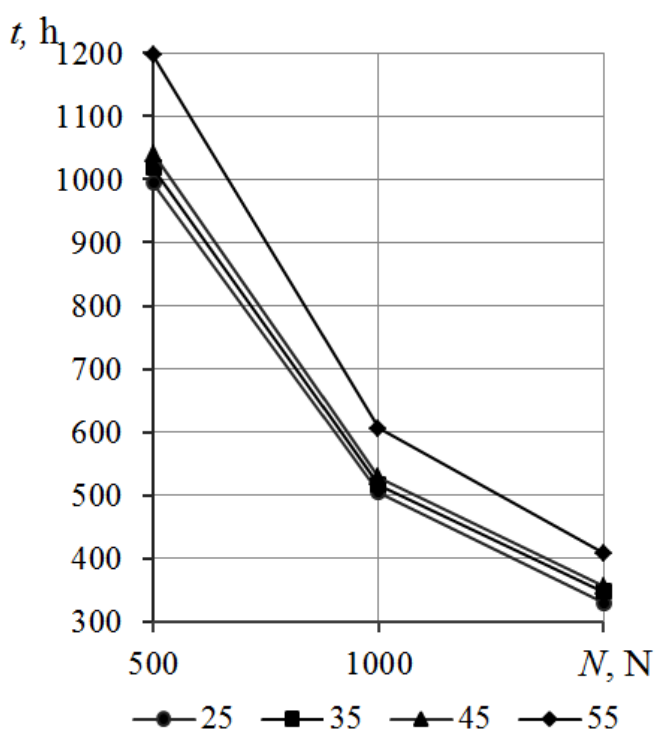

(a)

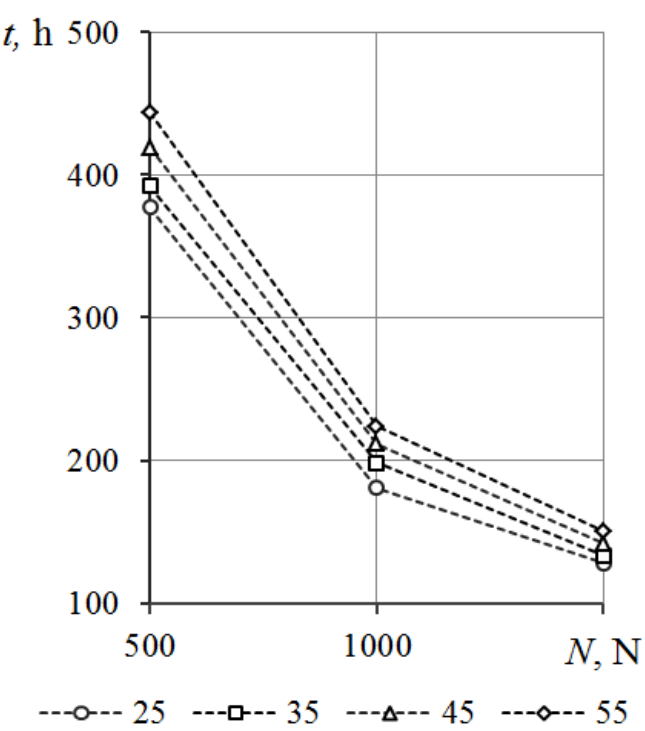

(b)

Figure 8. Influence of temperature on the bearing resource (dry friction): (a) PA6+30\%CF; (b) PA6+30\%GF

When the acceptable wear $h_{1 \max }=1.0 \mathrm{~mm}$ is achieved, there is an increase in the resource with increasing ambient temperature: by $20 \%$ in the bearing with a carbon-composite bushing and by $17 \%$ in the bearing with a glass-composite bushing. At all loads such dependence is practically identical.

The resource of a bearing with a carbon composite bushing is significantly greater than with a glass composite (Figure 9).

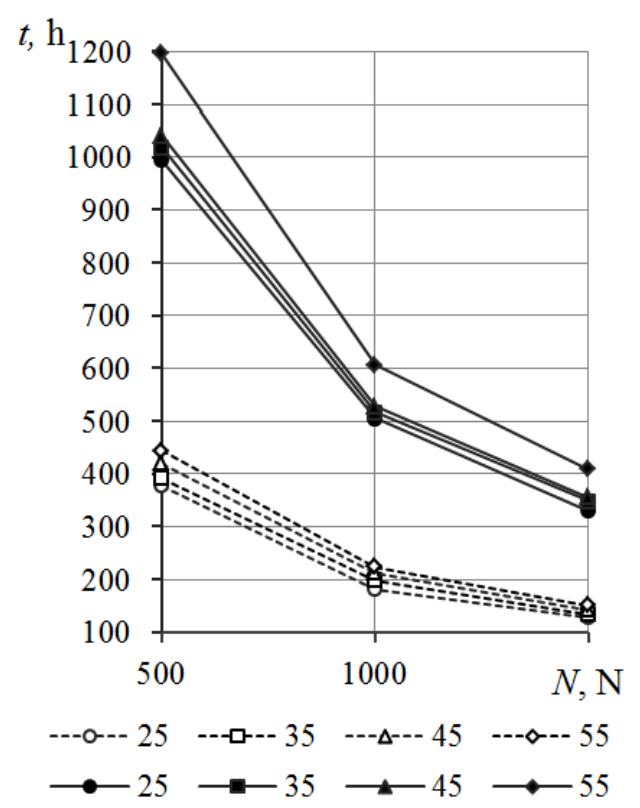

Figure 9. Comparison of the bearing resources under dry friction

The ratio of resources of both MP bearings under dry friction will be approximately the same for all loads at $T=25-45^{\circ} \mathrm{C}$ : at $N=500 \mathrm{~N}$ it is $248 . .264 \%$, at $N=1000 \mathrm{~N}$ it is $250 \ldots 264 \%$, at $N=1500 \mathrm{~N}$ it is $250 \ldots 260 \%$. At $T=55^{\circ} \mathrm{C}$ for all loads $N$ this ratio is higher up to $271 \%$.

Figure 10 shows the calculated resources of MP bearings for both types of friction. 


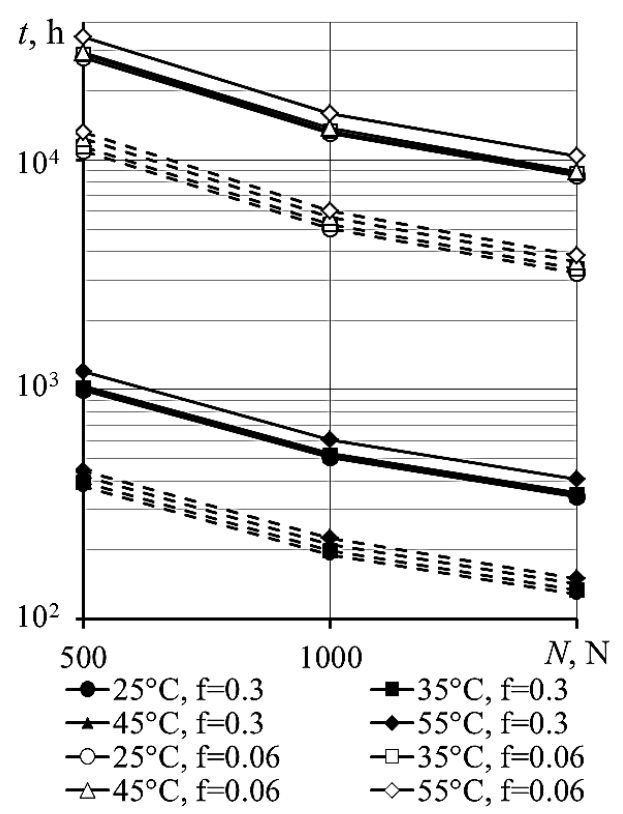

Figure 10. Resource of MP bearings under dry and boundary friction

A decrease in the coefficient of friction five times under boundary friction compared to dry friction causes an increase in the resource of the MP bearings by several times. In particular, at $N=1500 \mathrm{~N}$ it is $25 \ldots 25.6$ times with increasing temperature, at $N=1000 \mathrm{~N}$ it is $25.9 \ldots 26.8$ times, at $N=500 \mathrm{~N}$ it is $28.1 \ldots 29.8$ times.

\section{Conclusions}

1. An increase in the ambient temperature causes a decrease in the value of the Young's modulus of polyamide composites $\mathrm{PA} 6+30 \% \mathrm{CF}$ and $\mathrm{PA} 6+30 \% \mathrm{GF}$, resulting in a decrease in the level of the initial maximum contact pressures $p(0)$. That is, the increase in temperature causes a decrease in the rigidity of polymer composites, which has a positive effect on the bearing capacity of MP bearings (up to 10\%). When the bushing wears, the patterns of further reduction of the initial maximum contact pressures $p(0)$ remain similar to the initial pressures.

2. With increasing ambient temperature there is an increase in the resource of MP bearings. That is, the higher temperature has a positive effect on the resource of MP bearings (up to $22 \%$ ). The calculated resource under boundary friction of the bearing with the carbon composite bushing will be higher by $240 \ldots 270 \%$ than with the glass composite bushing. Under dry friction the similar correlation of resources takes place.

3. It is established that the resource of MP bearings increases approximately on a square dependence on decrease in coefficient of sliding friction

4. The developed analytical method of calculation of MP sliding bearings provides at a design stage an effective predictive estimation of their contact parameters and the resource taking into account influence of ambient temperature.

Author Contributions: Conceptualization, M.C.; methodology, M.C.; investigation, M.C., A.K.; formal analysis, M.P.; funding acquisition, M.P.; writing - review and editing, A.K.; software, A.K.; validation, A.B.

Funding: This research received no external funding.

Conflicts of Interest: The authors declare no conflict of interest.

\section{References}

1. Wielieba, W. Maintenance-free plain bearings made of thermoplastic polymers; Wyd. Wrocław University of Science and Technology: Wrocław, Poland, 2013. 
2. Feyzullahoglu, E.; Saffak Z. The tribological behavior of different engineering plastics under dry friction conditions. Materials and Design 2008, 29, 205-211. https://doi.org/10.1016/j.matdes.2006.11.012

3. Demirci, M.T.; Düzcükoğlu, H. Wear behaviors of Polytetrafluoroethylene and glass fiber reinforced Polyamide 66 journal bearings. Materials \& Design 2014, 57, 560-567. https://doi.org/10.1016/j.matdes.2014.01.013

4. Miler, D.; Škec, S.; Katana, B.; Žeželj, D. An Experimental Study of Composite Plain Bearings: The Influence of Clearance on Friction Coefficient and Temperature. Strojniški vestnik - Journal of Mechanical Engineering 2019, 65(10), 547-556. https://doi.org/10.5545/sv-jme.2019.6108

5. Juanjuan Zhu; Fang Xie; Dwyer-Joyce,R.S. PEEK Composites as Self-Lubricating Bush Materials for Articulating Revolute Pin Joints. Polymers 2020, 12(3), 665. https://doi.org/10.3390/polym12030665

6. Zorko, D.; Kulovec, S.; Duhovnik, J.; Tavcar, J. , Durability and design parameters of a Steel/PEEK gear pair. Mechanism and Machine Theory 2019, 140, 825-846. https://doi.org/10.1016/j.mechmachtheory.2019.07.001.

7. Kindrachuk, M.; Volchenko, A.; Volchenko, D.; Volchenko, N.; Poliakov, P.; Tisov, O.; Kornienko, A. Polymers with enhanced energy capacity modified by semiconductor materials. Functional Materials 2019, 26(3), 629634. doi:https://doi.org/10.15407/fm26.03.629

8. Goryacheva, I.G. Mechanics of frictional interaction; Nauka: Moscow, Russia, 2001.

9. Kragelsky, I.V.; Dobychin, N.M.; Kombalov, V.S. Fundamentals of Friction and Wear Calculations; Mashinostroenie: Moscow, USSR, 1977.

10. Kuzmenko, A.G. Development of methods of contact tribomechanics; KhNU: Khmelnytsky, Ukraine, 2010.

11. Teplyy, M.I. Determination of contact parameters and wear in cylindrical sliding bearings. Friction and wear 1987, 6, 895-902.

12. Usov, P.P. Internal contact of cylindrical bodies of close radii during wear of their surfaces. Friction and wear 1985, 3, 404-414.

13. Dykha, A.; Marchenko, D. Prediction the wear of sliding bearings. International Journal of Engineering $\mathcal{E}$ Technology 2018, 7 (2.23), 4-8. http://dx.doi.org/10.14419/ijet.v7i2.23.11872

14. Sorokatyi, R.; Chernets, M.; Dykha, A.; Mikosyanchyk, O. Phenomenological model of accumulation of fatigue tribological damage in the surface lauer of materials. Mechanisms and Machine Science 2019, 73, 3761-3769. https://doi.org/10.1007/978-3-030-20131-9 371

15. Zwieżycki, W. Forecasting the reliability of the wearing parts of machines; ITE: Radom, Poland, 1999. in Poland

16. Sorokatyi, R.V. Modeling the behavior of tribosystems using the method of triboelements. Journal of Friction and Wear 2002, 23(1), 16-22.

17. Sorokatyi, R.V. Solution of the problem of wear of a fine elastic layer with a rigid bearing mounted on a rigid shaft using the method of triboelements. Journal of Friction and Wear 2003, 24(1), 35-41.

18. Rezaei, A.; Ost, W.; Van Paepegem, W.; De Baets, P.; Degrieck, J. Experimental study and numerical simulation of the large-scale testing of polymeric composite journal bearings: Three-dimensional and dynamic modeling. Wear 2011, 270, 431438. https://doi.org/10.1016/j.wear.2010.11.005

19. Rezaei, A.; Ost, W.; Van Paepegem, W.; De Baets, P.; Degrieck, J. A study on the effect of the clearance on the contact stresses and kinematics of polymeric composite journal bearings under reciprocating sliding conditions. Tribology International 2012, 48 , 8-14. https://doi.org/10.1016/j.triboint.2011.06.031

20. Rezaei, A.; Van Paepegem, W.; De Baets, P.; Ost, W.; Degrieck, J. Adaptive finite element simulation of wear evolution in radial sliding bearing. Wear 2012, 296(1-2), 660-671. https://doi.org/10.1016/j.wear.2012.08.013

21. Andreikiv, M.V., Chernets, M.V. Evaluation of the contact interaction of rubbing machine elements; Naukova Dumka: Kiev, Ukraine, 1991. c. in Russion

22. Chernets, M.; Pashechko, M.; Nevchas, A. Methods of forecasting and increasing the wear resistance of tribotechnical sliding systems. In 3 volumes. Vol.1. Research and calculation of sliding tribosystems, methods to increase durability and wear resistance; KOLO: Drogobich, Ukraine, 2001.

23. Chernets, M.; Pashechko, M.; Nevchas, A. Methods of forecasting and increasing the wear resistance of tribotechnical sliding systems. In 3 volumes. Vol. 2. Surface reinforcement of structural materials of sliding tribosystems; KOLO: Drogobich, Ukraine, 2001.

24. Chernets, M.V.; Andreikiv, O.E.; Liebiedieva, N.M.; Zhydyk, V.B. A model for evaluation of wear and durability of plain bearing with small out-of-roundness. Materials Science 2009, 2, 279-290. https://doi.org/10.1007/s11003-009-9176-5

25. Chernets, M.V. Prediction of the life of a sliding bearing based on a cumulative wear model taking into account the lobing of shaft contour. Journal of Friction and Wear 2015, 36(2), 163-169. https://doi.org/10.3103/S1068366615020038

26. Chernets, M.V. Contact problem for a cylindrical joint with technological faceting of the contours of its parts. Materials Science 2009, 6, 859-868. https://doi.org/10.1007/s11003-010-9252-x

27. Chernets, M.; Chernets, Ju. Generalized method for calculating the durability of sliding bearings with technological out-of-roundness of details. Proc. IMechE. Part J: Journal of Engineering Tribology 2015, 229(2), 216-226. https://doi.org/10.1177/1350650114554242

28. Budynas, R.G.; Nisbett, J.K. Shigley's Mechanical Engineering Design, 11 ed.; McGraw-Hill: New York, USA, 2019.

29. Chernets, M.V.; Shil'ko, S.V.; Pashechko, M.I.; Barshch, M. Wear resistance of glass- and carbon-filled polyamide composites for metal-polymer gears. Journal of Friction and Wear 2018, 39(5), 361-364. https://doi.org/10.3103/S1068366618050069

30. Chernets, M.; Kindrachuk, M.; Kornienko, A. Methodology of calculation of metal-polymer sliding bearings for contact strength, durability and wear. Tribology in Industry 2020, 42(4), 572-584. https://doi.org/10.24874/ti.900.06.20.10 